Working Paper

in Economics and

Development Studies

Department of Economics

Padjadjaran University

No. 200907

\title{
Volatility Model for Financial \\ Market Risk Management : \\ An Analysis on JSX Index \\ Return Covariance Matrix
}

Erie Febrian

Finance \& Risk

Management Study Group

(FRMSG)

Aldrin Herwany

Research Division,

Laboratory of Management

Faculty of Economics,

Padjadjaran University

September, 2009

Center for Economics and Development Studies, Department of Economics, Padjadjaran University Jalan Cimandiri no. 6, Bandung, Indonesia.

Phone/Fax: +62-22-4204510

http://www.lp3e-unpad.org

For more titles on this series, visit:

http://econpapers.repec.org/paper/unpwpaper/ 


\title{
Volatility Model for Financial Market Risk Management : An Analysis on JSX Index Return Covariance Matrix
}

\author{
Abstract \\ Erie Febrian (erie_febrian@fe.unpad.ac.id) \\ Finance \& Risk Management Study Group (FRMSG) FE UNPAD, Indonesia \\ Mail to: erie_febrian@fe.unpad.ac.id \\ Aldrin Herwany (herwany@yahoo.com) \\ Research Division, Laboratory of Management FE UNPAD, Indonesia \\ Mail to: herwany@yahoo.com
}

In measuring risk, practitioners have practiced one of the two extreme approaches for so long, i.e. historical simulation or risk metrics. Meanwhile, academicians tend to apply methods based on the latest development in financial econometrics. In this study, we try to assess one of important issues in financial econometric development that focuses on market risk measurement and management employing asset-based models, i.e. models that apply dimensional covariance matrix, which is relevant to practice world. We compare covariance matrix model with Exponential Smoothing Model and GARCH Derivation and the Associated Derivation Models, using JSX Stock price Index data in 2000-2005. The result of this study shows how applicable the observed financial econometric instrument in Financial Market Risk Management practice.

Keywords:

Risk Management, Volatility Model 


\section{Introduction}

Practitioners and academicians seem to approach risk measurement in two different perspectives. Practitioners tend to apply one of the two utmost approaches for so long, i.e. historical simulation or risk metrics. On the other side, academicians tend to use methods emerging from the latest development in financial econometrics (Andersen, Bollerslev, Christoffersen, and Diebold, 2005). Academicians believe that the developed tools incorporate time-varying financial asset return volatilities and correlations with persistent dynamics, better than the former approaches. In addition, the discipline of financial econometrics pays extensive attention to time-varying volatility and the relevant measurement, modeling and forecasting instruments, as asset return volatilities are now central to finance, whether in asset valuation, portfolio management, or market risk measurement (Engle, 2001).

Nevertheless, it is also believed that the development of financial econometrics will result in models that meet the practitioners' interest. In this study, we observe the application of GARCH Derivation and the associated derivation models, including $\mathrm{ARCH}, \mathrm{GARCH}, \mathrm{EGARCH}$, and TGARCH, especially to the practices of market risk measurement and management. We expect to end up with a midway solution that bridges interests of practitioners and academicians. We base our analysis on a relatively high frequency (daily) set of data in order to diminish the estimation errors (Greene, 2000).

\section{Obstacles from Dealing With Financial Time Series}

There are some problems occurring when a financial model is developed using financial time series (Hassan \& Shamiri, 2005), especially those of high frequency data. First of all, financial time series often reveal volatility clustering. In such a circumstance, large changes tend to be followed by large changes and small changes by small changes. Secondly, the series often exhibit leverage effects in the sense that changes in stock prices tend to be negatively correlated with changes in volatility. This implies that volatility is higher after negative shocks than after positive shocks of the same enormity. Finally, the series often show leptokurtosis, i.e. the distribution of their returns is heavily tailed.

Meanwhile, we cannot employ traditional regression tools to overcome the abovementioned obstacles as they have been proven limited in the modeling of high-frequency data. The tools assume that that only the mean response could be changing, while the variance stays constant over time. This is impractical, as financial series demonstrate clusters of volatility, which can be identified graphically.

Engle (1982) proposed Auto-Regressive Conditional Heteroscedastic (ARCH) models to alleviate the first two problems, i.e. volatility clustering and leptokurtosis. Such models provided new instruments for measuring risk, and the associated influence on return. The models also provided new means for pricing and hedging non-linear assets. To overcome the third constraint, i.e. leptokurtosis, the ARCH models were then generalized. Bollerslev (1986) introduced Generalized Auto-Regressive Conditional Heteroscedastic (GARCH), which were then advanced into some derivations, such as EGARCH (Nelson, 1991) and TGARCH (Zakoian, 1994). Nevertheless, GARCH models often do not fully portray the heavy tails property of high frequency data. Therefore, the application of non normal distribution, such as Student- $t$, generalized error distribution (GED), Normal-Poisson, is inevitable. Additionally, adaptive exponential smoothing methods allow smoothing parameters to change over time, in order to adapt to changes in 
the characteristics of the time series. In this paper, we compare covariance matrix model with Exponential Smoothing Model and GARCH Derivation and the Associated Derivation Models.

\section{The Models: Exponential Smoothing \& GARCH Derivation}

\subsection{Exponential Smoothing}

With a large history of observations available, variance estimator can be written in the simple exponential smoothing recursive form with smoothing parameter, $\alpha$ :

$\hat{\sigma}_{t}^{2}=\alpha \varepsilon_{t-1}^{2}+(1-\alpha) \hat{\sigma}_{t-1}^{2} \quad$ Where $\alpha_{t-1}=\frac{1}{1+\exp \left(\beta+\mathcal{W}_{t-1}\right)}$

Some researchers have argued that a smoothing parameter should be allowed to change over time in order to adapt to the latest characteristics of the time series. Since exponential smoothing for volatility forecasting is formulated in terms of variance forecasts, $\hat{\sigma}_{t-1}^{2}$, RiskMetrics (1997) suggests the following minimization:

$\min \sum_{i}\left(\varepsilon_{i}^{2}-\hat{\sigma}_{i}^{2}\right)^{2}$

\subsection{Auto-Regressive Conditional Heteroscedastic (ARCH)}

ARCH was firstly developed by Bachelier in 1900s, before Mandelbrot (1963) advanced this method in observing economics and finance variables. He stated that non conditional distribution had thick tails, variance changed over time, and each change, small or large, would usually be followed by another change. Several years later, Engle (1982) developed this approach by assuming that error value of ARCH mode is normally distributed with mean $=0$ and non constant variance or $h_{t}=\alpha_{0}+\alpha_{1} \varepsilon^{2}{ }_{t-1}+\ldots+\alpha_{q} \varepsilon^{2}{ }_{t-q}$, or $\sigma_{t}^{2}=\alpha_{0}+\sum_{i=1}^{q} \alpha_{i} \varepsilon_{t-i}^{2}$

where the equation ensures that variance is positive, or explicitly stated as: $\alpha_{0}>0$ dan $\alpha_{i} \geq 0, \quad i=1, \ldots q$.

\subsection{Generalized Auto-Regressive Conditional Heteroscedastic (GARCH)}

The GARCH model was developed independently by Bollerslev (1986) and Taylor (1986). The GARCH model allows the conditional variance to be dependent upon previous own lags, so that the conditional variance equation in the simplest case is now 


$$
\sigma_{t}^{2}=\alpha_{0}+\alpha_{1} u_{t-1}^{2}+\beta \sigma_{t-1}^{2}
$$

This is a GARCH(1,1) model. $\sigma_{t}^{2}$ is known as the conditional variance since it is a one-period ahead estimate for the variance calculated based on any past information thought relevant.

GARCH is considered better than ARCH as the former is more parsimonious, and avoids over fitting. Consequently, the model is less likely to breech non-negativity constraints.

The GARCH$(1,1)$ model can be extended to a $\operatorname{GARCH}(p, q)$ formulation, where the current conditional variance is parameterized to depend upon $q$ lags of the squared error and $p$ lags of the conditional variance:

$$
\begin{aligned}
& \sigma_{t}^{2}=\alpha_{0}+\alpha_{1} u_{t-1}^{2}+\alpha_{2} u_{t-2}^{2}+\ldots+\alpha_{q} u_{t-q}^{2}+\beta_{1} \sigma_{t-1}^{2}+\beta_{2} \sigma_{t-2}^{2}+\ldots+\beta_{p} \sigma_{t-p}^{2} \\
& \sigma_{t}^{2}=\alpha_{0}+\sum_{i=1}^{q} \alpha_{i} u_{t-i}^{2}+\sum_{j=1}^{p} \beta_{j} \sigma_{t-j}^{2}
\end{aligned}
$$

But in general a GARCH(1,1) model will be sufficient to capture the volatility clustering in the data, and rarely is any higher order model estimated or even entertained in the academic finance literature.

\subsubsection{Exponential Generalized Auto-Regressive Conditional Heteroscedastic (EGARCH)}

The exponential GARCH model was proposed by Nelson (1991). There are various ways to express the conditional variance equation, but one possible specification is given by

$$
\log \left(\sigma_{t}^{2}\right)=\omega+\beta \log \left({\sigma_{t-1}}^{2}\right)+\gamma \frac{u_{t-1}}{\sqrt{\sigma_{t-1}^{2}}}+\alpha\left[\frac{\left|u_{t-1}\right|}{\sqrt{\sigma_{t-1}^{2}}}-\sqrt{\frac{2}{\pi}}\right]
$$

The model has several advantages over the pure GARCH specification. First, since the $\log \left(\sigma_{t}^{2}\right)$ is modeled, then even if the parameters are negative, $\sigma_{t}^{2}$ will be positive. There is thus no need to artificially impose non-negativity constraints on the model parameters. Second, asymmetries are allowed for under the EGARCH formulation, since if the relationship between volatility and returns is negative, $\gamma$, will be negative.

Note that in the original formulation, Nelson assumed a Generalized Error Distribution (GED) structure for the errors. GED is a very broad family of distributions that can be used for many types of series. However, due to its computational ease and intuitive interpretation, almost all applications of EGARCH employ conditionally normal errors as discussed above rather than using GED.

\subsubsection{Threshold Auto-Regressive Conditional Heteroscedastic (TARCH)}

TARCH or Threshold ARCH was introduced independently by Zakoian (1990) and Glosten, Jaganathan and Runkle (1993). This Specification for the conditional variance is given by

$$
\sigma_{t}^{2}=\omega+\alpha u_{t-1}^{2}+\gamma d_{t-1} u_{t-1}^{2}+\beta \sigma_{t-1}^{2}
$$


Where $d_{t}=1$ if $u_{t}>0$, and 0 otherwise. In this model, good news $\left(u_{t}>0\right)$, and bad news $(u<0)$, have differential effects on the conditional variance-good news has an impact of a, while bad news has an impact of $(\alpha+\gamma)$. If $\gamma>0$ we say that the leverage effect exists. If $\gamma \neq 0$, the news impact is asymmetric.

\section{Empirical Results}

The following empirical evidence from financial market, i.e. stock-index data, which is collected on a daily basis. We start the first part of this sub chapter by showing the descriptive data, to see characteristic of JSX data. We then continue to the second part by conducting data analysis through the description of mean model (ARMA) and volatility model (ARCH-GARCH).

\subsection{Data}

Figure 1 below plots 1,437 daily returns of JSX from January 25, 2000 to December, 2001. The variability is not uniform, and shows chunks mixed with occasional spikes. Let $e_{t}$ (residual at time $\left.\mathrm{t}\right)=$ return at time $\mathrm{t}-$ sample mean. Then, the squared residual $e_{t}^{2}$ estimates the variance of the return for $\mathrm{t}$. The plot of the squared residuals does not appear to follow a random process. Also, similar values of squared residuals come in chunks.

\section{Figure 1}

Daily Closing Price of JSX 2000-2005

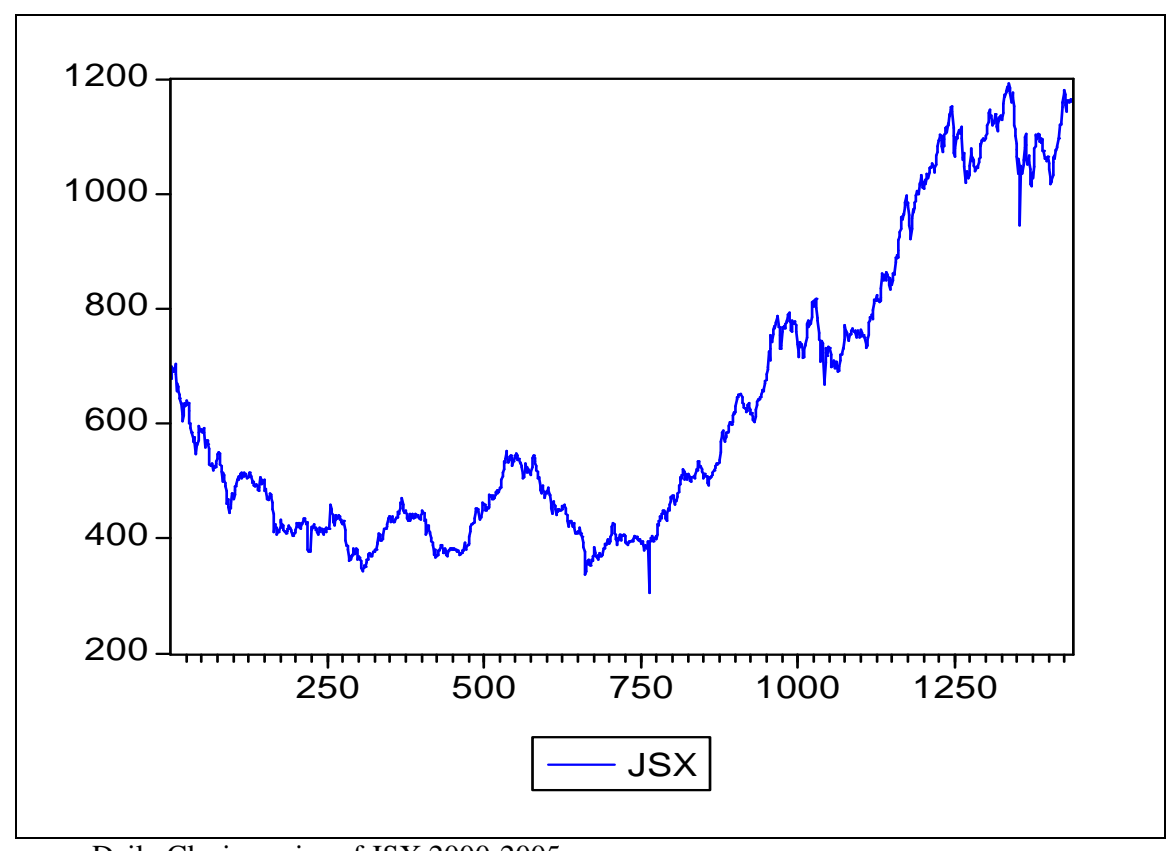

Daily Closing price of JSX 2000-2005

We try to transform JSX data into logarithm, which can be seen on figure 2, above right. The result of this logarithm process in fact does not provide significant change. We then conduct a differencing (see figure 2 , below left) on the resulting logarithm, so that we can see the stationary mean data. Nevertheless, this 
result still reveals non constant variance. Visually, we can see that JSX data still reflects high volatility. On the last phase, we carry out 2-step data transformation, i.e. logarithm transformation and differencing transformation, which result in stationary mean and variance. This result can visually be seen on figure 2 , below right.

Figure 2

\section{Transformation of Daily Closing Price of JSX 2000-2005}

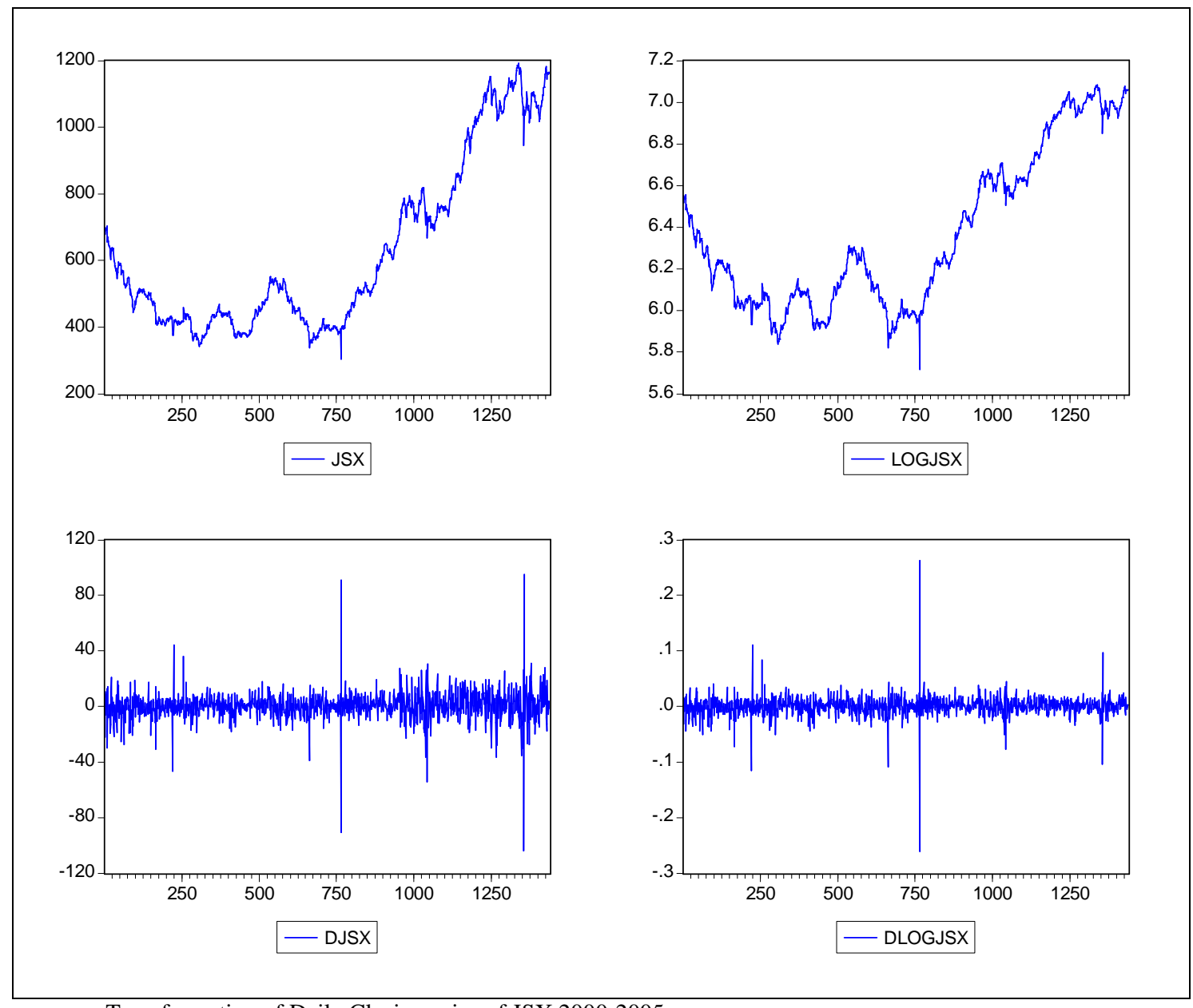

Transformation of Daily Closing price of JSX 2000-2005

Financial asset returns that provide a motivation for the ARCH class of models, is known as "volatility clustering" or "volatility pooling". Volatility clustering describes the tendency of large changes in asset prices (of either sign) to follow large changes and small changes (of either sign) to follow small changes. In other words, the current level of volatility tends to be positively correlated with its level during the immediately preceding periods. This phenomenon is demonstrated in the Figure 2, below right. Meanwhile, leverage effects shows the tendency for volatility to rise more following a large price fall than following a price rise of the same enormity. 


\subsubsection{Histogram and Statistics}

We can formally test the failure of these normality properties and we shall consider these tests. Kurtosis measures the concentration of values around the mean or the peakedness of the distribution, a high concentration of excessively peaked around zero (Fat Tails). Leptokurtosis measures the tendency for financial asset returns to have distributions that exhibit fat tails and excess peaked ness at the mean. Meanwhile, Skewness is important when a distribution is not symmetric and has one tail longer than another. A normal distribution has zero skewness and a kurtosis coefficient of 3.

We find kurtosis is greater than 3 (i.e. 71,6259), and it show negative skewness (left or right). The high kurtosis value reveals a great change in JSX returns that form high volatility. The Jarque-Bera statistic, which is a test for normality based on the $3^{\text {rd }}$ and $4^{\text {th }}$ moments, indicates a clear rejection of normality for the JSX returns. JSX data indicates too many observations around the central point of approximately zero return and significant outliers.

Figure 3

Histogram and Statistics of JSX Returns for January 2000 - December 2005

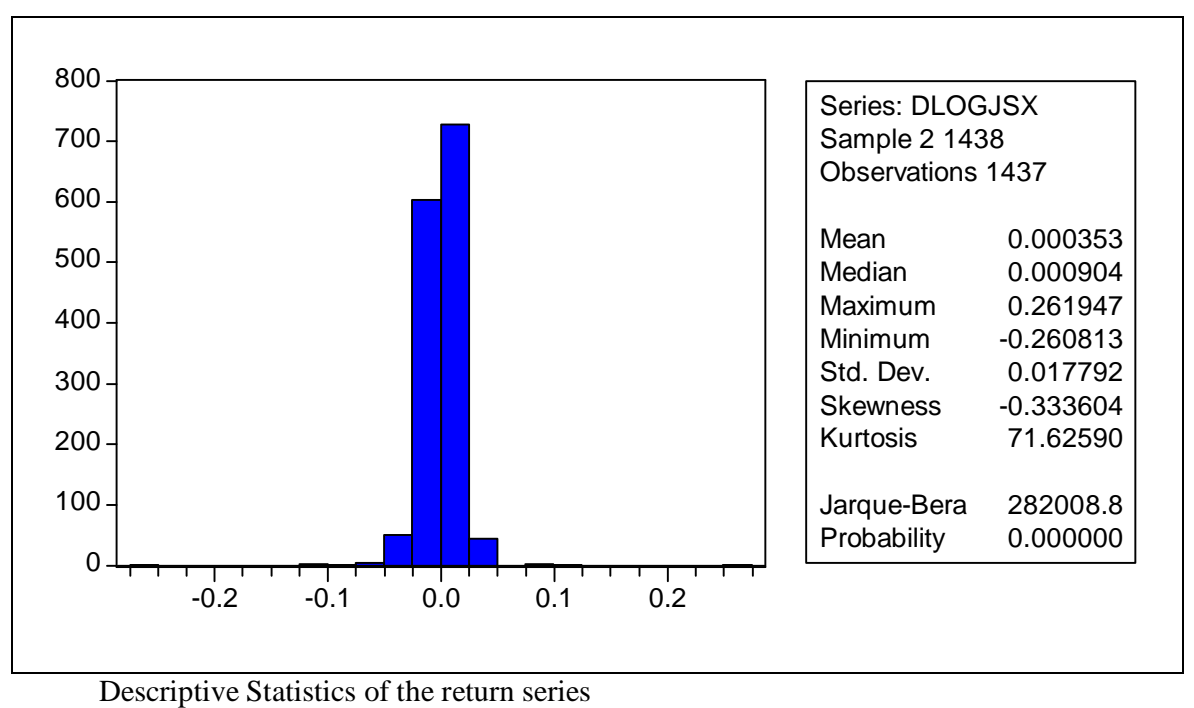

\subsubsection{Q-Q Plots}

QQ-Plot is data plotting that has been divided on the basis of quantile group. This plot shows whether the plotted data is scattered around the 45-degree line (i.e. the data is normally distributed) or not. From figure 4 we can see that JSX return data is not dispersed along the line, which means the data is not normally distributed.

From our autocorrelation test using correlogram, we conclude that ACF are highly significant at all lags. Q-Stats are also highly significant. This dependence of the variance at time $t$ on variances of preceding 
periods is called the conditional heteroscedasticity. Conditional heteroscedasticity is quite common for high frequency asset return data. Conditional heteroscedasticity may be present for daily returns, but it may not be so for the monthly returns

Figure 4.

QQ Plot of JSX Returns Standardized by the Average Volatility

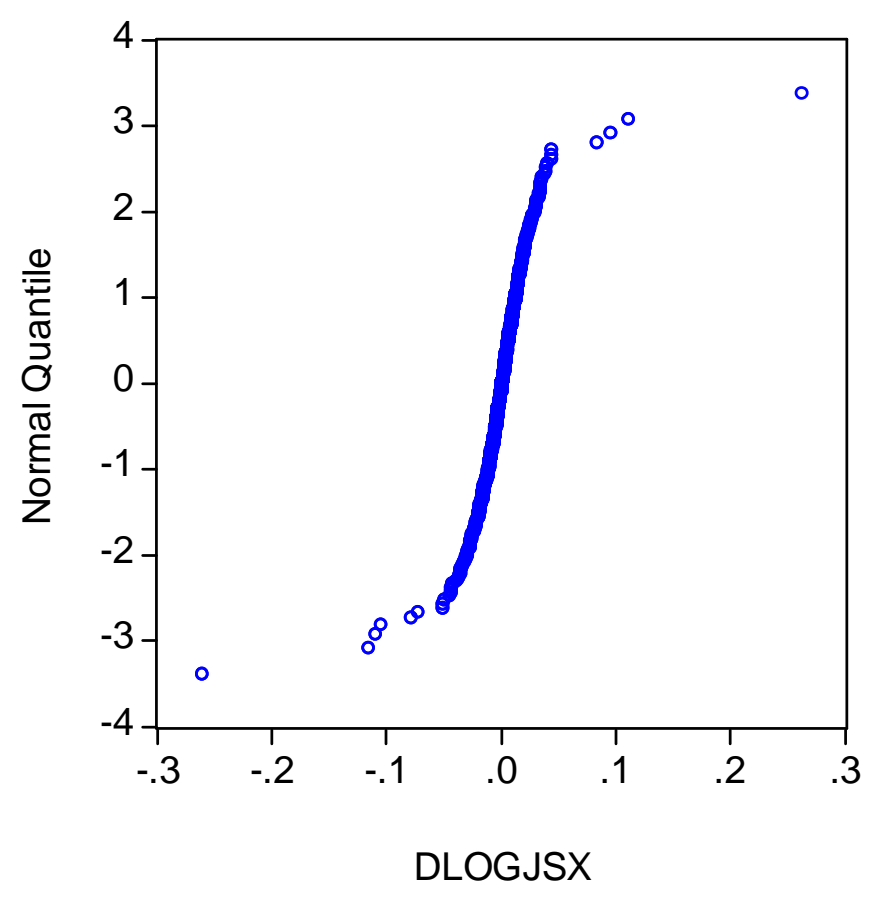

Notes to Figure: We show quantiles of daily JSX returns from January 2000 to December 2005, standardized by the average daily volatility during the sample, against the corresponding quantiles from a standard normal distribution.

\subsection{Empirical and Analysis}

We identify number of orders required to form ARCH and GARCH models through Mean model, i.e. ARMA. From the application of this approach, we determine number of orders $(\mathrm{P}, \mathrm{Q})$ that are necessary to construct ARCH-GARCH models.

\subsubsection{Mean Model}

Our data calculation shows that regression coefficient $\operatorname{AR}(1)$ is significant at any confidence interval level, and so is MA(1). However, when we employ both variables (AR \& MA) at the same time in the calculation, we find that the independent variables are not significant. The calculation also reveals that AR model is better than that of MA, where $\mathrm{R}^{2}$ of $\mathrm{AR}(10,49 \%)$ is greater than that of MA $(10,45 \%)$. In addition, SIC value of AR is the least, and the result of correlogram-based autocorrelation test shows that 
AR's residual reaches White Noise. Therefore, in developing ARCH model, we start by using AR variable.

Table 1:

Results for the JSX Mean Equation

\begin{tabular}{|l|l|l|l|c|l|l|l|l|}
\hline \multicolumn{1}{|c|}{ Models } & $\begin{array}{c}\text { R- } \\
\text { Squared }\end{array}$ & $\mathbf{R}^{\mathbf{2}}$ - Adj & $\begin{array}{c}\text { S.E. of } \\
\text { Regression }\end{array}$ & $\begin{array}{c}\text { Sum } \\
\text { squared } \\
\text { resid }\end{array}$ & $\begin{array}{c}\text { Log } \\
\text { likelihood }\end{array}$ & DW stat & $\begin{array}{c}\text { Akaike info } \\
\text { criterion }\end{array}$ & $\begin{array}{c}\text { Schwarz } \\
\text { criterion }\end{array}$ \\
\hline AR(1) & 0.010498 & 0.009808 & 0.017690 & 0.448744 & 3757.325 & 1.999014 & -5.230257 & -5.222918 \\
\hline MA(1) & 0.010455 & 0.009765 & 0.017705 & 0.449807 & 3758.741 & 1.999131 & -5.228588 & -5.221253 \\
\hline ARMA(1,1) & 0.010504 & 0.009123 & 0.017696 & 0.448741 & 3757.329 & 1.999897 & -5.228871 & -5.217862 \\
\hline
\end{tabular}

This table presents the first for Trial and Error

\subsubsection{Volatility Model}

We employ ARCH estimate to end up with results showing no ARCH effect. The simplest model for volatility is the historical estimate. Historical volatility simply involves calculation of variance or standard deviation of returns in the usual way over some historical period, and this then becomes the volatility forecast for all future periods. Historical volatility is still useful as a benchmark for comparing the forecasting ability of more complex time models. In the preliminary data calculation, we get JSX mean of 0,000353 for exponential smoothing model. The associated variance and SIC are 0,000317 and 5,215803 , respectively. To obtain better results, our model selection starts from the use of volatility model, which is characterized by constant conditional variance. We begin using ARCH and GARCH model by employing various orders (P,Q), as can be seen on table 2 .

From table 2, we can see that among the models of ARCH(1), ARCH (2), GARCH $(1,1)$ and GARCH $(2,1), \operatorname{GARCH}(1,1)$ is the only model that has insignificant mean at any significance level (i.e. $1 \%, 5 \%$ or $10 \%)$. Therefore, at this preliminary level, we have only 3 models left, whose all parameters are significant. Among the remaining models, $\mathrm{ARCH}(1)$ with significance level of $1 \%$ has the least SIC, i.e. - 5,471105. ARCH(1) also results in significant variance at any level of significance. To assess whether the obtained data suits the model, we conduct an ARCH test, which can reveal the existence of ARCH effect. Residual value emerging from the modeling is determined by the value of $e_{t}$, which is independent over time. Autocorrelation tests reveal that the value of ARCH LM test is not significant, i.e. 0,873905, as it is greater than significance level of 0,05 , or even 0,01 . Therefore, the value of variance residual resulting from $\mathrm{ARCH}(1)$ shows that the obtained data suits the model and does not contain $\mathrm{ARCH}$ effect. In the ARCH test, the null and alternative hypothesis are respectively, $\mathrm{H}_{0}:$ ARCH effect exists, $\mathrm{H}_{\mathrm{a}}$ : ARCH effect does not exist. Both the F-statistics and the LM-statistic are not significant, suggesting the absence of ARCH in the JSX index returns. 
Tabel 2

Result for The JSX Volatility Model

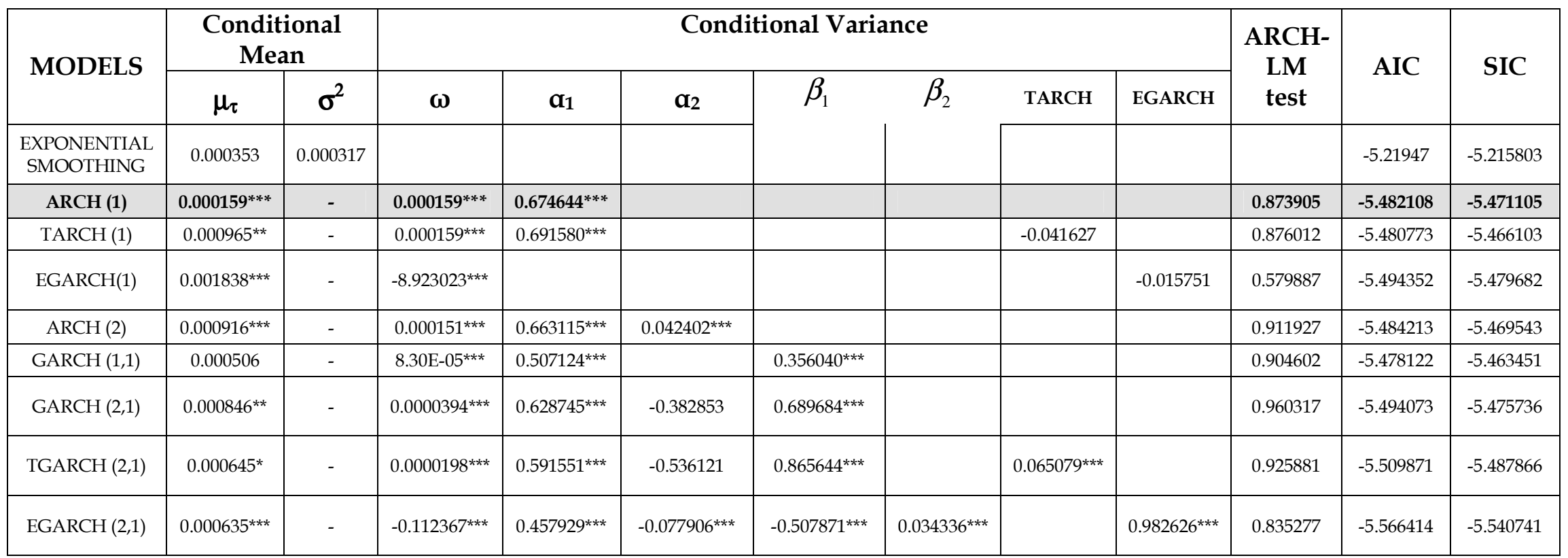

Note : This table presents the results of the four models for the conditional mean and conditional variance of JSX daily return from Jan.4, 2000 to Dec. 31, 2005, a total of 1,248 observations.

* significant at confidence level of $10 \%$

** significant at confidence level of $5 \%$

$* * *$ significant at confidence level of $1 \%$ 
After getting the best temporary model, we add regressor variable into the model to assess the autocorrelation relationship occurring on the next variance. To reveal the existence of volatility clustering, we detect the outliers, as well as deterministic shift in volatility. Then we use dummy variable to alleviate the outlier problem, i.e. we add dummy variable into the equation to eliminate the outlier (the outlier can be seen on figure 2, below right). The associated results can be seen on table 3 .

From table 3, we can see that the addition of regressor variables of both AR(1) and AR(2) into the model gives a better result at any significance level than that of ARCH (1) model with the least SIC. This implies that AR(2) - ARCH (1) model provides an equation that fits our JSX data. Additionally, SIC indicator that is used to select the best temporary model can adjust to the increased number of parameters with the increased number log likelihood when conflict occurs. However, AR(2)-ARCH (1) cannot be directly used as the best model in spite of its least SIC, as its $\mathrm{R}^{2}$-adj value is negative, which is meaningless. Therefore, we add dummy variable to improve the model (see, Aggarwal, Inclan and Leal,1999). The use of dummy variable results in new model (i.e. AR(2) - ARCH(1) - Dummy model) that increases $\mathrm{R}^{2}$-adj value to $13,79 \%$ (positive) which proves that the resulting volatility model gets improved through the addition of dummy variable, as well as predictor variable AR. The mean of AR(2)ARCH-Dummy model is 0,000928 and therefore significant. Meanwhile, the mean for variance of 0,000158 is also significant. The requirement of regression coefficient for $\omega>0, \alpha>0, \beta \geq 0$ and $\alpha+\beta+$ $\mathrm{d}<1$ is fulfilled. Furthermore, the test on residual value of AR(2)-ARCH-Dummy does not find autocorellation with ARCH-LM test of 0,869587, which is greater than any significance level of $10 \%, 5 \%$ and $1 \%$. Table 4 shows the results of AR(2)-ARCH-Dummy model test. Figure 6 exhibits the standard deviation as computed through the equation of AR(2)-ARCH(1)-Dummy. 
Tabel 3

Results of The JSX Volatility Model + Regressor + Dummy

\begin{tabular}{|c|c|c|c|c|c|c|c|c|c|c|c|c|}
\hline \multirow[b]{2}{*}{ MODELS } & \multicolumn{4}{|c|}{ Conditional Mean } & \multicolumn{5}{|c|}{ Conditional Variance } & \multirow[b]{2}{*}{$\begin{array}{l}\text { ARCH- } \\
\text { LM test }\end{array}$} & \multirow[b]{2}{*}{ AIC } & \multirow[b]{2}{*}{ SIC } \\
\hline & $\mu_{\tau}$ & $\mathbf{d}_{1}$ & $\phi_{1}$ & $\phi_{2}$ & $\omega$ & $\boldsymbol{\alpha}_{1}$ & $\beta_{1}$ & $\begin{array}{c}\text { TARCH } \\
\left(\gamma_{1}\right) \\
\end{array}$ & $\begin{array}{c}\text { EGARCH } \\
\left(\gamma_{1}\right) \\
\end{array}$ & & & \\
\hline $\operatorname{AR}(2)-\operatorname{ARCH}(1)$ & $0.001004 * * *$ & - & $0.192461 * * *$ & $-0.069778^{* * *}$ & $0.000151 * * *$ & $0.683754 * * *$ & - & & & 0.985454 & -5.509484 & -5.49113 \\
\hline $\begin{array}{l}\operatorname{AR}(2)-\operatorname{ARCH}(1) \\
\text { DUM }\end{array}$ & $0.000928^{* * *}$ & $0.318977 * * *$ & $0.207155^{* * *}$ & $-0.072143 * * *$ & $0.000158 * * *$ & $0.520782 * * *$ & - & & & 0.869587 & -5.512386 & -5.49036 \\
\hline $\begin{array}{l}\text { AR(2) - TARCH } \\
\text { DUM }\end{array}$ & $0.000798 * *$ & $0.318609 * * *$ & $0.210418^{* * *}$ & $-0.071113^{* * *}$ & $0.000153 * * *$ & $0.450547 * * *$ & - & $0.224266^{* * *}$ & & 0.879642 & -5.50872 & -5.483018 \\
\hline $\begin{array}{l}\text { AR(2) - EGARCH } \\
\text { DUM }\end{array}$ & $0.000957 * * *$ & 0.364364 & $0.172753^{* * *}$ & $-0.061851^{* * *}$ & $-8.840397 * * *$ & $0.604969 * * *$ & - & & $-0.089555 * * *$ & 0.944319 & -5.506625 & -5.480923 \\
\hline
\end{tabular}

Note : This table presents the results of the four models for the conditional mean and conditional variance of JSX daily return from Jan.4, 2000 to Dec. 31,

2005 , a total of 1,248 observations. The value of $\mathrm{R}^{2}$-adj of AR(2)-ARCH(1) DUM is $13,99 \%$

$*$ significant at confidence level of $10 \%, * *$ significant at confidence level of $5 \%, * * *$ significant at confidence level of $1 \%$

Tabel 4

Results of AR(2)-ARCH(1)-Dummy test

\begin{tabular}{|c|c|c|c|c|}
\hline & Coefficient & Std. Error & z-Statistic & Prob. \\
\hline $\begin{array}{c}\text { C } \\
\text { DUM } \\
\text { AR(1) } \\
\text { AR(2) }\end{array}$ & $\begin{array}{r}0.000928 \\
0.318977 \\
0.207155 \\
-0.072143\end{array}$ & $\begin{array}{l}0.000322 \\
0.109235 \\
0.027266 \\
0.020186\end{array}$ & $\begin{array}{r}2.880015 \\
2.920083 \\
7.597564 \\
-3.573858\end{array}$ & $\begin{array}{l}0.0040 \\
0.0035 \\
0.0000 \\
0.0004 \\
\end{array}$ \\
\hline \multicolumn{5}{|c|}{ Variance Equation } \\
\hline $\begin{array}{c}\mathrm{C} \\
\mathrm{ARCH}(1)\end{array}$ & $\begin{array}{l}0.000158 \\
0.520782 \\
\end{array}$ & $\begin{array}{l}4.28 \mathrm{E}-06 \\
0.023940 \\
\end{array}$ & $\begin{array}{l}36.91321 \\
21.75395 \\
\end{array}$ & $\begin{array}{l}0.0000 \\
0.0000 \\
\end{array}$ \\
\hline $\begin{array}{l}\text { R-squared } \\
\text { Adjusted R-squared } \\
\text { S.E. of regression } \\
\text { Sum squared resid } \\
\text { Log likelihood } \\
\text { Durbin-Watson stat }\end{array}$ & $\begin{array}{l}0.140866 \\
0.137860 \\
0.016508 \\
0.389431 \\
3961.137 \\
2.210602\end{array}$ & \multicolumn{2}{|c|}{$\begin{array}{l}\text { Mean dependent var } \\
\text { S.D. dependent var } \\
\text { Akaike info criterion } \\
\text { Schwarz criterion } \\
\text { F-statistic } \\
\text { Prob(F-statistic) }\end{array}$} & $\begin{array}{r}0.000365 \\
0.017779 \\
-5.512386 \\
-5.490356 \\
46.86046 \\
0.000000\end{array}$ \\
\hline
\end{tabular}


Figure 6

Graph of the Standard Deviation as Computed

Through AR(2)-ARCH(1)-Dummy Equation

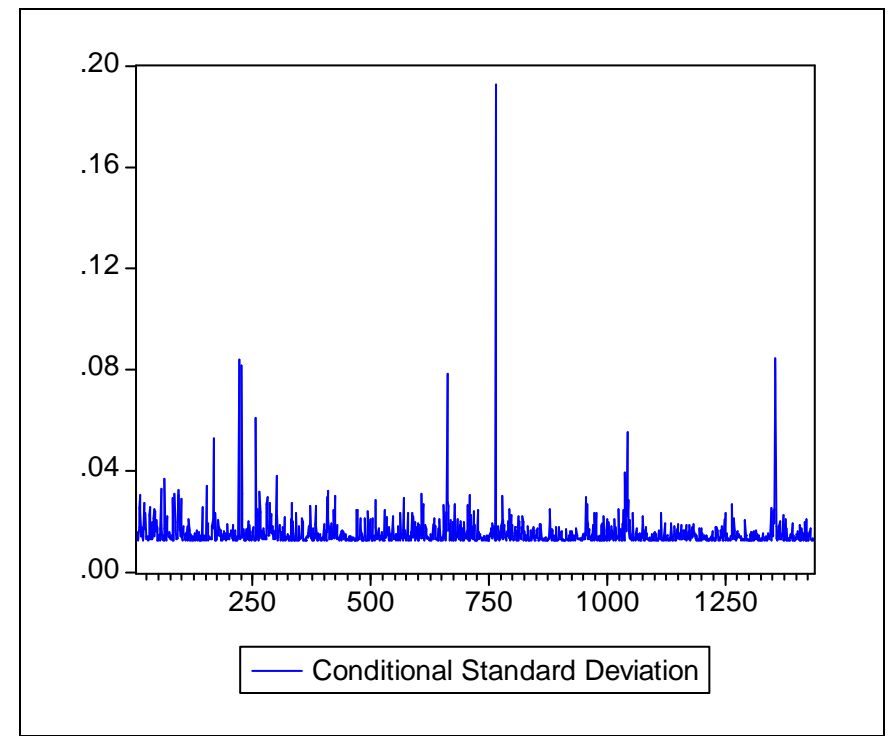

The result of ARCH-LM test on residual can be seen on table 5 .

Tabel 5

ARCH Test:

Residual Test on AR(2) - ARCH(1)-Dummy

\begin{tabular}{llll}
\hline \hline F-statistic & 0.026919 & Probability & 0.869699 \\
Obs*R-squared & 0.026956 & Probability & 0.869587 \\
\hline \hline
\end{tabular}

Test Equation:

Dependent Variable: STD_RESID^2

Method: Least Squares

Date: 02/30/06 Time: 16:47

Sample(adjusted): 51438

Included observations: 1434 after adjusting endpoints

\begin{tabular}{crrrr}
\hline \hline Variable & Coefficient & Std. Error & t-Statistic & Prob. \\
\hline \hline C & 1.043425 & 0.147326 & 7.082422 & 0.0000 \\
STD_RESID^2(-1) & -0.004336 & 0.026426 & -0.164070 & 0.8697 \\
\hline \hline
\end{tabular}

ARCH-LM test is simple $\mathrm{TR}^{2}$ from the regression which has an asymptotic $\chi_{\mathrm{p}}^{2}$ distribution. The null hypotheses that $\phi_{1}=\ldots=\phi_{\mathrm{p}}=0$ which would indicate that there is no persistence in the conditional variance. We then try to detect the existence of Asymmetric Effect and Leverage Effect on the AR(2)$\mathrm{ARCH}(1)$-Dummy model, and alleviate them to ensure the accuracy of the chosen model. 


\subsubsection{Asymmetry in Volatility}

We assess the model to reveal asymmetric effect by using cross autocorrelation between standardized and squared standardized residuals or TARCH model (Zakoin 1994). The asymmetric effect often occurs in financial data, in which downward shocks cause higher volatility in the near future than positive shocks do. On table 3, we can see the existence of asymmetric effect through the coefficient of TARCH $\left(\gamma_{1}\right)$, which has positive value and is significant at any significance level. This effect emerges as the JSX financial data tends to reflect a leptokurtosis. On table 3, the TARCH coefficient is 0,224266 (i.e greater than zero) and significant, meaning a good news. This implies that the negative shock on JSX returns instigates higher volatility shortly than do the positive one.

\subsubsection{Leverage effect.}

We employ EGARCH model to assess the existence of Leverage effect on the volatility model. As it incorporates exponential function, EGARCH is capable for adjusting a model whose variance increases over time. Table 3 shows the existence of leverage effect, which is represented by the EGARCH coeffeicient $\left(\gamma_{1}\right)$ that is negative and significant. From the data calculation, we find EGARCH coefficient $(\gamma)$ of -0.089555 , which reveals the existence the leverage effect.

\section{Conclusion and Discussion}

Exponential smoothing is an estimation model, which is only based on the mean movement without properly calculating variance fluctuation. In that case, this model often fails to explain the changing variance level. Meanwhile, a high level volatility and volatility clustering is often found in financial data, as well as in the practice of risk management. Therefore, we employ ARCH and GARCH models to alleviate such problems.

Based on the above calculation, we can encapsulate that $\mathrm{AR}(2)-\mathrm{ARCH}(1)-\mathrm{Dummy}$ model is the best approach to assess and to predict risk of JSX index. ARCH-GARCH model is very suitable for asset risk assessment and estimation in short term, which is represented by the value of variance estimate. For long term, both models can be used to assess a trade-off between risk and return of an asset. AR(2) ARCH(1)Dummy Model is also proven to be better than an ordinary prediction model such as exponential smoothing, as SIC of the former (-5.49) is less than that of the former $(-5.22)$.

\section{References}

Aggrawal Reena, Inclan Carla and Leal Ricardo, 1999, Volatility in Emerging Stock Markets, Journal of Financial and Quantitative Analysis, 34, 33-54, USA

Andersen Torben G, TimBollerslev, Diebold Francis X and Labys Paul, 2003, Modeling and Forecasting Realized Volatility, Econometrica, 71, 579-625, USA

Andersen, T.G., T. Bollerslev, P.F. Christoffersen, and F.X. Diebold, 2005. "Practical Volatility And Correlation Modeling For Financial Market Risk Management." Working Paper 11069, National Bureau Of Economic Research, Massachusetts.

Bollerslev, T. 1986. "Generalized Autoregressive Conditional Hetroscedasticity." Journal of Econometrics. 31. 307-327. 
Engle Robert, 2001, GARCH 101: ARCH/GARCH Models in Applied Econometrics, Journal of Economic Perspective, 15, 157-168, USA

Engle, R.F. (1982) - Autoregressive conditional heteroskedasticity with estimates of the variance of UK inflation, Econometrica, 50, pp. 987-1008;

Fiorentini Gabriele, Sentana Enrique and Shepard Neil, 2004, Likelihood-Based Estimation Generalized ARCH Structures, Econometrica, 72, 1481-1517, USA

Greene William H, 2000, Econometric Analysis, Handbook of Econometrics, $3^{\text {rd }}$ ed, New York University, USA

Gwilym Owain and Sutcliffe Charles, 2001, Problem Encountered When Using High Frequency Financial Market data : Suggested Solutions, Journal of Financial Management and Analysis, 14, 38-51, USA

Harvey Campbell R and Siddique Akhtar, 1999, Autoregressive Conditional Skewness, Journal of Financial and Quantitative Analysis, 34, 465-487, USA

Hassan, A., A.Shamiri, 2005. "Modeling and Forecasting Volatility in Malaysian and Singaporean Stock Market". Working Paper, Universiti Kebangsaan Malaysia

Jensen Soren Tolver and Rahbek Anders, 2004, Asymptotic Normality of the QMLE Estimator of ARCH in the Nonstationary Case, Econometrica, 72, 641-646, USA

Mandelbrot, B. 1963. "The Variation of Certain Speculative Prices." Journal of Business. 36, 394-419.

Morgan J.P, 1997, CreditMetrics-Technical Document " The Benchmark for understanding credit risk", Bank of America, New York.

Nelson, Daniel B. (1991) - Conditional Heteroskedasticity in Asset Returns: A New Approach, Econometrica, 59, 347-370;

Taylor, S.J. (1986) - Modelling Financial Time Series, John Wiley;

Zakoian, J. M. 1994. "Threshold Heteroscedastic Models." Journal of Economic Dynamic and Control. 18. 931-955. 